\title{
Construction and Practice of Student Innovation Laboratory Based on School-Enterprise Cooperation
}

\author{
Hua Liu \\ College of Engineering and Technology \\ Tianjin Agricultural University \\ Tianjin, China \\ 41599386@qq.com \\ Weiyu Zhang \\ College of Engineering and Technology \\ Tianjin Agricultural University \\ Tianjin, China \\ 525156985@qq.com
}

\author{
Yong Wei \\ College of Engineering and Technology \\ Tianjin Agricultural University \\ Tianjin, China \\ 595183963@qq.com \\ Yu Shi \\ College of Engineering and Technology \\ Tianjin Agricultural University \\ Tianjin, China \\ syych83@tjau.edu.cn
}

\begin{abstract}
In order to improve the innovation ability and competitive ability of engineering college students, combined with the present situation of practical teaching in Engineering \& Technology Institute of Tianjin Agricultural University, the paper introduces the construction and practice of innovation laboratory based on school enterprise cooperation. It mainly includes the construction of teachers, teaching reform and cultural construction. The integration of college teachers and enterprise elites can improve students' creative thinking and innovation ability, and improve students' engineering ability. Cultural construction can provide students with more role models and motivation. The practice shows that the construction of innovation laboratory based on the cooperation between colleges and enterprises can increase the number of innovative projects, the number of participants, the number of students participating in intellectual property and the number of students. Through the practice of the actual project, the students' innovation ability, especially the employment ability has been greatly improved.
\end{abstract}

Keywords-Enterprise Employment Demand, School Enterprise Cooperation, Engineering Education, Innovative Ability

\section{INTRODUCTION}

At present, the types of science and technology competition and skills competition for college students, students comprehensive, innovative projects are increasing year by year. It has made a positive reform in the mode and method of innovative talents training, and has been widely loved by college teachers and students. The improvement of the teaching method has also prompted the university to invest more energy in the construction of the teaching platform. How to create a better environment for the development of students and the platform is currently a hot research in the field of education. At the same time, with the social demand of talents is increasing, and the cultivation of college students' innovation and practical

1. Guidance- Development Program on Educational Reform and Innovation for Teachers of Tianjin Agricultural University (20171005).

2. Non agriculture special project of Tianjin Agricultural University (01101). ability of creation has become the trend of development of education all over the world, and the laboratory is an important base for students to carry out teaching research and practice[1].

With the concept of CDIO engineering education to the construction of innovation laboratory, can not only strengthen its application characteristics, completely change the traditional "To give priority to teaching, supplemented by practice" theory over practice teaching mode, but also to realize the demand design as the main driving force of the practice training mode. The multi - level and multi - enterprise cooperation framework provides a new way for the cooperation between colleges and enterprises. In this kind of practical cooperation framework, we can establish more practical and feasible innovation laboratory, which can be used to simulate the working environment and technical training. At the same time, it can quickly improve students' innovation ability, and cultivate innovative, complex and applied talents that meet the needs of social enterprises. After innovative laboratory training with innovative practice ability of students, after graduation can be directly into the enterprise work, to achieve employment without waiting[2].

On the basis of the comprehensive laboratory, the college has established a scientific and technological innovation laboratory based on school enterprise cooperation, adhering to the concept of "facing the public, taking care of the elite". "For the public" is to allow the vast majority of students to participate in the formation of a strong foundation for the masses of students, and "care for the elite" is to make some outstanding students stand out. The students' science and technology innovation laboratory is a professional platform for most students, and becomes a part of excellent students to give full play to their practical ability and innovative consciousness. 


\section{CONSTRUCTION OF EXPERIMENT PlatForm BASED ON CAMPUS-ENTERPRISE COOPERATION}

In the process of promoting the construction of innovation laboratory, the emphasis is on the three aspects of teachers' construction, teaching reform and cultural atmosphere. Laboratory oriented public philosophy, the students' engineering practice ability as the basis, in the "enterprise school laboratory" on the basis of "business needs - Project - to enhance the ability of students" as the main line to encourage innovation, and actively explore and create special atmosphere for science and technology innovation[3]. Major construction framework is as shown in Fig. 1:

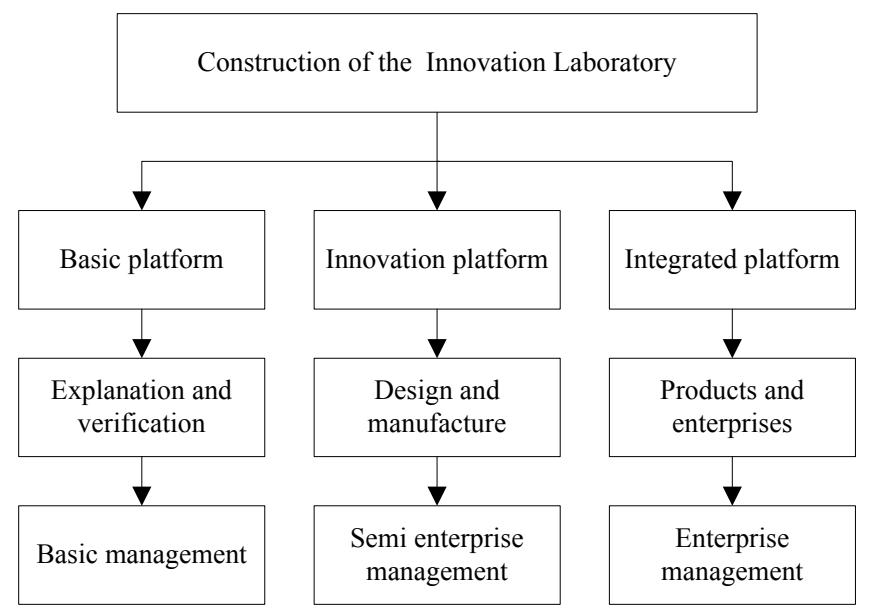

Fig. 1. The Experiment Teaching Team for Agricultural Electrification and Automation Experiment Teaching Demonstration Center

In the process of construction, the laboratory adopts progressive construction, progressive teaching and progressive management, combined with the needs of the enterprise, so that students can be stricter, and constantly improve the ability of engineering practice.

\section{A. Teachers construction}

The main function of colleges and universities is to cultivate talents and scientific research. The cultivation of talents in Colleges and universities is to cultivate the applied talents to meet the needs of social development, which not only puts forward the requirements for the theoretical foundation of the university teachers, but also has a higher expectation for the accumulation of practical experience. But the teachers in Colleges and universities and university cooperation cannot get a lot of experience, and only the enterprises and scientific research institutions jointly to observe the social needs and market changes, so as to cultivate talents to meet the social development. Although the enterprise to understand the social dynamics, find social and market demand, but its research ability compared to universities and research institutions is insufficient, in order to improve the market competitiveness, enterprises should strengthen cooperation with universities and research institutions. [4].

(a) To establish a collaborative innovation laboratory of college and enterprise, broaden the channels of cooperation; (b) Regularly sent teachers to the cooperative enterprise training, understand the enterprise production and management of the whole process, improve the ability to set up personnel training objectives for professional market research, cultivate more "double quality" of high quality teachers; the business elite school, teachers and students in training.

\section{B. Education reform}

In the aspect of teaching reform, we should pay attention to the "mass education", and vigorously promote the independent management mode of the application, implementation and achievement of science and technology innovation projects; To further improve the modern experimental teaching system for " Phased training, Multi-level promotion, All-round training", continue to explore the idea of opening laboratory reform elasticity, to strengthen the cultivation of students' autonomous learning ability, to further explore the path of cultivating cooperative learning and study of students, and to cultivate team spirit to meet the needs of the society, so that the students' ability of innovation, comprehensive ability, engineering ability and experimental ability, etc., can be cultivated and trained, and the training goal of "thick foundation, wide caliber, strong ability and high quality" is achieved.[5].

The enterprise elite in the student innovation laboratory will be the management of enterprises, personnel assessment system and cost accounting system and other aspects of the university laboratory, and set up the practical teaching guarantee mechanism and performance evaluation system for university.

\section{Cultural construction}

Laboratory culture is based on the laboratory management and operation as the center, by the laboratory of all staff, experimental teachers and students to shape the formation of the pursuit of ideals, professionalism, group awareness, unity and harmony and harmony as the theme of the cultural atmosphere. In particular, laboratory culture includes environmental culture, behavioral culture, institutional culture and spiritual culture. Environmental culture mainly refers to the laboratory hardware equipment, the layout of the laboratory the environment. Behavior culture refers to the laboratory management personnel, teachers and students in the long-term cultural behavior in the accumulation of the formation of the code of conduct. Institutional culture is the laboratory cultural activities of the guidelines. Spiritual culture refers to a variety of cultural expressions to guide the behavior of group members, psychological ideology, moral habits, values and so on[6].

Laboratory culture has the following four functions in the process of cultivating students' Innovative Ability. Major framework is as shown in Fig. 2. Good laboratory culture can in the course of its operation. A unique feature of the system, all kinds of material and spiritual factors exist in the covers, a variety of psychological and behavioral control of teachers and students. 


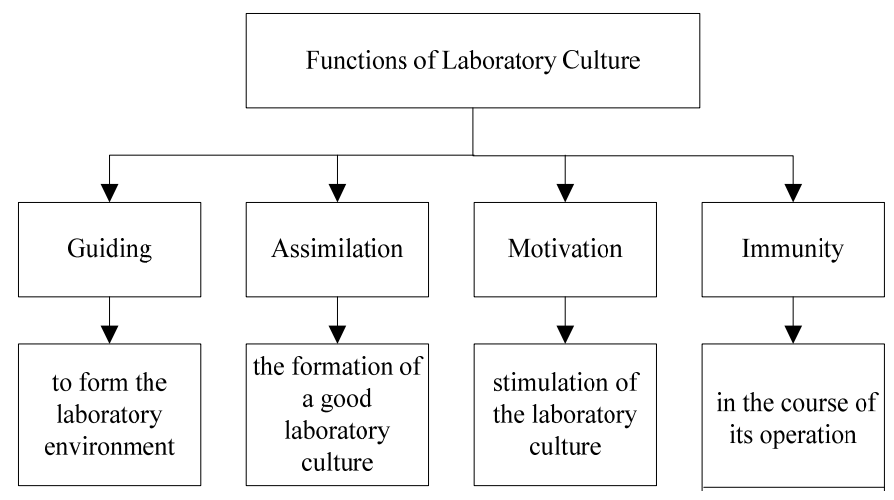

Fig. 2. Functions of Laboratory Culture

Laboratory construction is an important part of the cultural construction of the laboratory, and the construction of laboratory culture is an integral part of the campus culture construction and the overall education environment. The construction of laboratory culture, including the construction of laboratory environment and culture, is the need to improve the quality of experimental teaching. Laboratory culture construction of scientific, harmonious atmosphere, improve students' scientific literacy and realistic style, can stimulate the students' desire to explore and cultivate students' innovative

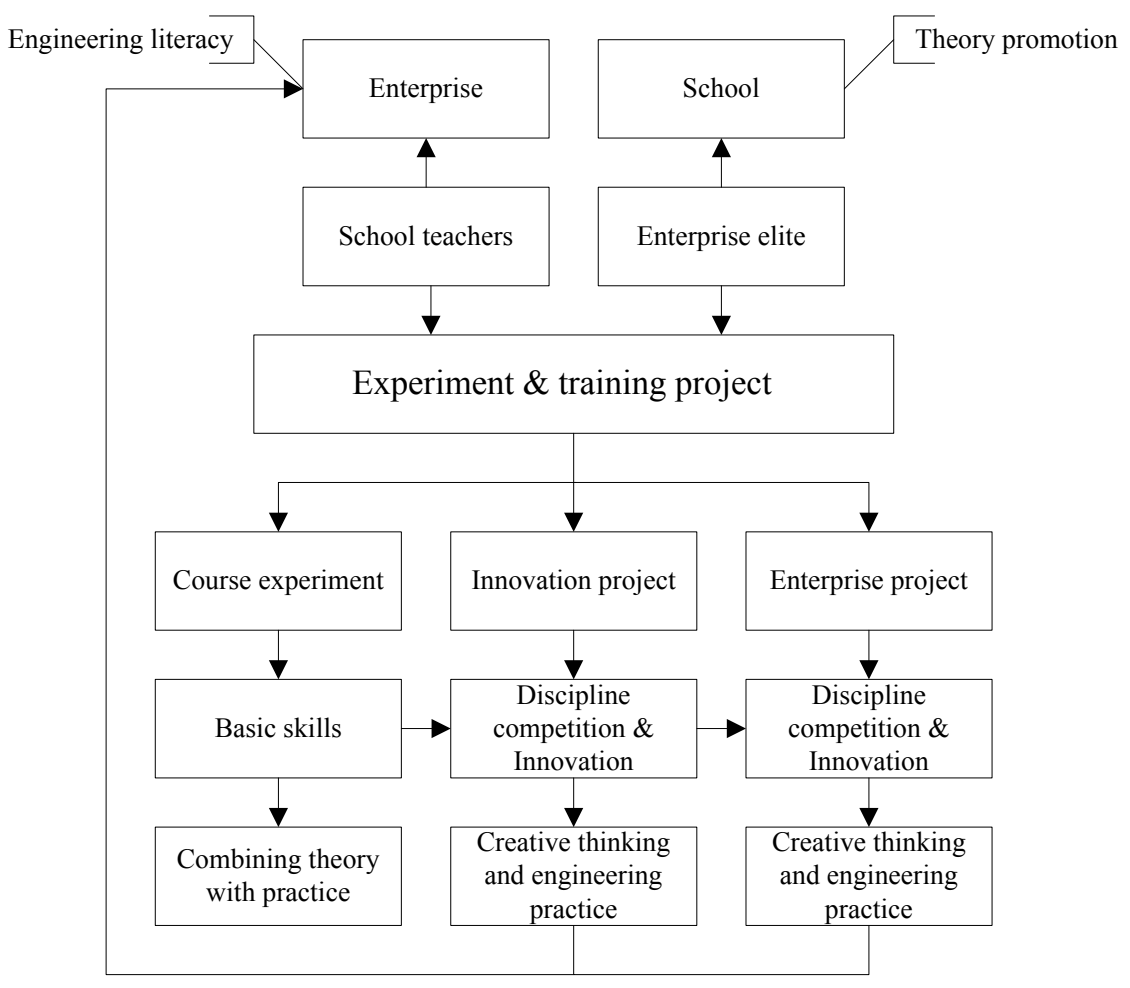

Fig. 3. Experiment \& Training Project Platform for Innovation Laboratory based on School- enterprise Cooperation

\section{SIGNIFICANT EXPERIMENT TEACHING EFFECT}

As is shown in Fig. 4, the students in innovation lab at the Tianjin Agricultural University College of engineering and technology, nearly three year students get the results as the spirit and practical ability, to cultivate students' good habits and literacy.

\section{Experiment \& training project platform}

As shown in Fig. 3, it is the construction for innovation laboratory based on school- enterprise cooperation . Its advantages are as follows:

(a) With the enterprise organization, advanced equipment, technology, management experience and technical personnel into the campus enterprise laboratory, can realize the mechanism of enterprise joint education and establish a comprehensive practice teaching platform,

(b) Under the guidance of college teachers and enterprise elites, the students realize the transition from the blind design to the plan design, the module division, the product trial production, and so on.

(c) On this platform, students are required to complete the learning tasks, but also to do preparatory work for the innovation project and the discipline competition. At the same time, on the basis of cooperation between enterprises and colleges and universities, students can shorten the time of adaptation and adjustment in the work of enterprises due to the participation of teachers and teachers. 
training of intellectual property rights and successfully obtained the patent authorization, they have entered into their own ideals and employers.

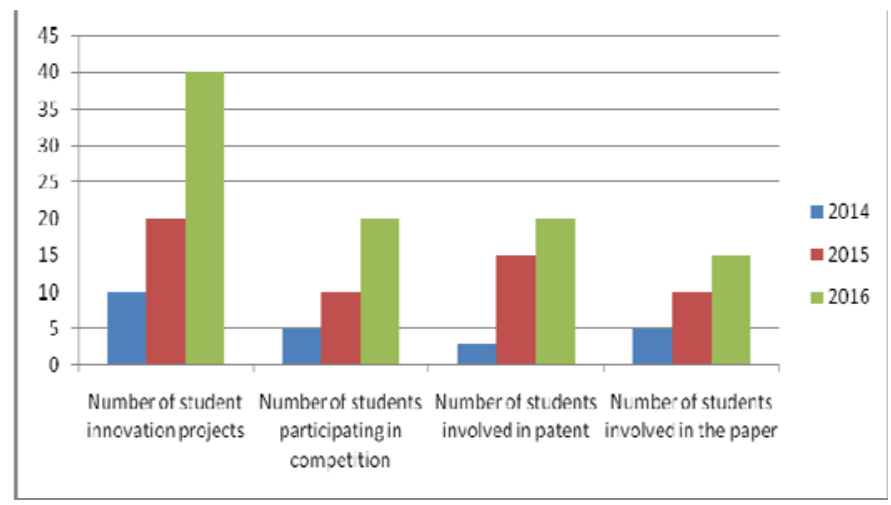

Fig. 4. Comparison of the Past Three Years

\section{CONCLUSIONS}

The purpose of the construction of the laboratory is to serve the personnel training, then scientific research laboratory has a high level of platform, high level of soft and hard conditions to carry out the experiment, to support the cultivation of innovative talents. The formation of a whole process of learning through the students, is relatively independent of the theoretical teaching system, and there is a clear teaching requirements and assessment methods of convergence, gradual and orderly practice and innovative teaching system.
The establishment of innovative laboratory based on school-enterprise cooperation, all the subjects have completed the comprehensive practical teaching reform, and optimized the practice teaching system and management mechanism, then has injected the new vigor for the school and the enterprise. It explores a new way for the practical teaching reform of engineering and technology institute.

\section{REFERENCES}

[1] Gao Youhua, Li Yanbin, Zhai Huiping, Sheng Yongshan, Jin Shi. Comprehensive Reform and Exploration of Practical Teaching for Mechanical and Electrical Specialty Based on Campus Enterprise Laboratory [J]. Experimental Technology and Management. 2016,13(33):241-245. (In Chinese)

[2] Yu Zhongan, Zhang Zhenli. To strengthen the construction of experimental teaching demonstration center to improve the quality of practice teaching $[\mathrm{J}]$. Journal of Jiangxi University of Science and Technology, 2010,06:49-52. (In Chinese)

[3] Gong Xianwei, Chen Yamin, Gong Tianjiao. Management and Construction of Open Laboratory Based on Cultivating Innovative Talents [J]. Experimental Technology and Management. 2016,33(33):271-273 (In Chinese)

[4] Wang Liyuan. Research of Teachers Development Mechanism in Industry-university-institute Cooperation [D]. Harbin Institute of Technology. 2013. (In Chinese)

[5] Wu Yuanzhou, Lv Heng-lin. Scientific Laboratory Promotion the Education of Creative Undergraduate with Melange of Teach and Research [J]. Experimental Technology and Management. 2016, 4(35):252-255. (In Chinese)

[6] Li Yudong, Liu Jingyan, Yan Youyun. Enhancing Practical Teaching Reform and Cultivating Outstanding Engineers Depending on Experimental Teaching Demonstraion Center[J]. Research and Explore in Laboratory, 2012,3(31):105-108. (In Chinese) 